\section{Acknowledging the gap between aspiration and achievement in improving social justice within Mada- gascar's conservation sector}

This special issue grew out of the conference "Voices from Madagascar's Forests" that was held in Norwich in June 2010 (Ferguson, 2010). Some forty people from many different countries including Madagascar participated in the event, among them people working within conservation programmes and for NGOs that are active in Madagascar, academics from the social sciences as well as from disciplines like geography, agroforestry and conservation biology.

Almost three years have passed since the discussions which led to the organising of the conference and to the production of this special issue took place. Those years have been challenging ones for Madagascar and the Malagasy, due to the ongoing political situation and its broader impacts on the economy and donor cooperation. The original observations which led to the call for better representation and rights for Malagasy forest-dependent people were drawn from experiences in the field and in various policy arenas on the island and abroad. They were based on the following series of observations recognised through academic publications. Firstly, forest-dependent people in Madagascar have often seen their de facto resource and land access rights threatened when conservation organisations begin interventions. Secondly, there is often a considerable gap between the discourse of conservation organisations, on the one hand, and the real, lived experience of local people, on the other. Conservation organisations' discourse is often spot on in social justice terms, aspiring to seek sustainable solutions for people to make a living. The challenge comes when looking at the actual practice of conservation on the ground as experiences of conservation policies' impacts on local people are not nearly as positive as the institutional discourse would suggest, this is despite the fact that over the course of the NEAP policies have been developed and implemented which were intended to be more people friendly. The third observation is that, the voice of Malagasy forest-dependent peoples is not heard and not listened to in conservation policy discussions.

Dealing first with the issue of land and resource rights, there have been various somewhat nebulous statements in places such as REDD policy documents, NGO websites and the literature around Madagascar's conservation sector in recent years about initiatives striving to improve rural Malagasy's land tenure security. However, until we reach a broad acceptance amongst all those involved in decision making over Malagasy land that there are many different but equally rightful forms of land tenure (including in the "state owned forests") although not legally recognised by the Malagasy state, we are likely to end only with stalemate in the discussion. Currently conservation policy is based on the premise that the local people don't own the forest which is going into one form of protection regime or another and, furthermore, that they are not able to manage their land themselves without some sort of externally initiated management system being put in place. In such a situation it is unlikely that rural Malagasy people will be provided with any real power or voice in the decision making processes over Madagascar's forests as essentially their right to make decisions about their own land and resources is not recognised. Alternative livelihoods and income generating activities would be a form of compensation for stopping practices such as swidden agriculture and production of fuelwood and construction materials, which those providing such alternatives claim rural Malagasy had no right to do in the first place.

The five essays included in this special issue address these problems and document the gap between aspiration and achievement in improving social justice within Madagascar's Conservation Sector. Many more case studies could be added, one only has to peruse the extensive literature published on the subject.

\section{ACKNOWLEDGEMENTS}

We would like to take this opportunity to thank the authors whose hard work and patience has led to the production of this special issue. We would like to particularly thank Nadine FritzVietta and Jacques Pollini for their important contributions to the process. Almost thirty anonymous reviewers provided insightful and helpful comments on the manuscripts submitted and the redrafts, we much appreciate their kindness. To Patrick, Lucienne, Christine and Arnaud we also must say a big thank you for providing the opportunity for serving as guest editors for this special issue, and for the substantial amount of time and effort they spent in helping us through the process and ensuring the final product was completed.

\section{Barry Ferguson}

University of East Anglia

U.K

ferguson.barry@gmail.com

\section{Eva Keller}

University of Zurich

Switzerland

e.s.keller@bluewin.ch

\section{REFERENCE}

Ferguson H.B. 2010, Voices from Madagascar's Forests: Improving Representation and Rights for Malagasy Forest Peoples, Final Report of the Conference held on the 5th/6th June 2010 at the School of International Development, University of East Anglia, Norwich, UK. $<$ http://www.academia.edu/593219/Voices_From_Madagascars_ Forests_Conference_Report_at 0724hrs > accessed 30th November 2012 


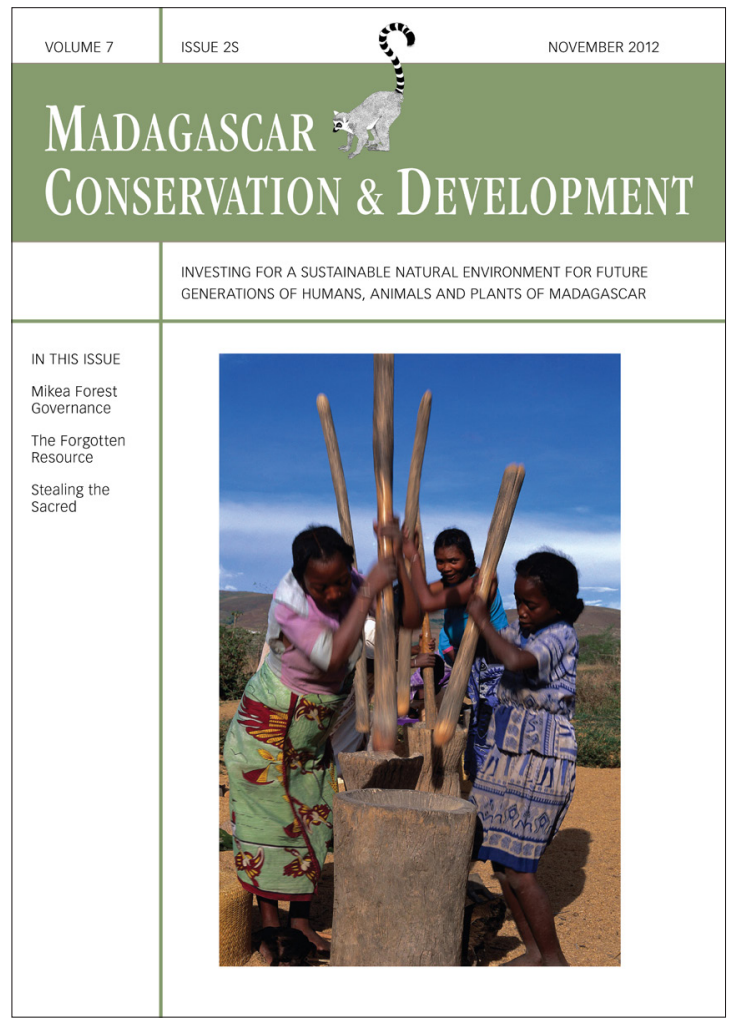

Madagascar Conservation \& Development is the journal of Indian Ocean e-Ink. It is produced under the responsibility of this institution. The views expressed in contributions to MCD are solely those of the authors and not those of the journal editors or the publisher.

All the Issues and articles are freely available at http://www.journalmcd.com

Contact Journal MCD

info@journalmcd.net for general inquiries regarding MCD funding@journalmcd.net to support the journal

Madagascar Conservation \& Development Institute and Museum of Anthropology University of Zurich

Winterthurerstrasse 190

$\mathrm{CH}-8057$ Zurich, Switzerland

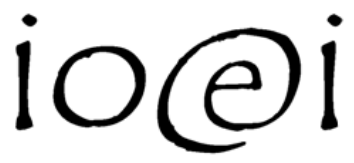

Indian Ocean e-Ink

Promoting African Publishing and Education www.ioeink.com

Missouri Botanical Garden (MBG)

Madagascar Research and Conservation Program BP 3391

Antananarivo, 101, Madagascar 